\title{
Uncinaria sanguinis sp. n. (Nematoda: Ancylostomatidae) from the endangered Australian sea lion, Neophoca cinerea (Carnivora: Otariidae)
}

\author{
Alan D. Marcus, Damien P. Higgins, Jan Šlapeta and Rachael Gray
}

Faculty of Veterinary Science, The University of Sydney, Sydney, New South Wales, Australia

\begin{abstract}
This study investigates the identity of hookworms parasitising the Australian sea lion, Neophoca cinerea (Péron), from three colonies in South Australia, Australia. The Australian sea lion is at risk of extinction because its population is small and genetically fragmented. Using morphological and molecular techniques, we describe a single novel species, Uncinaria sanguinis sp. n. (Nematoda: Ancylostomatidae). The new species is most similar to hookworms also parasitic in otariid hosts, Uncinaria lucasi Stiles, 1901 and Uncinaria hamiltoni Baylis, 1933. Comparative morphometrics offered limited utility for distinguishing between species within this genus whilst morphological features and differences in nuclear ribosomal DNA sequences delineated U. sanguinis sp. $\mathrm{n}$. from named congeners. Male specimens of $U$. sanguinis $\mathrm{sp}$. $\mathrm{n}$. differ from $U$. lucasi and $U$. hamiltoni by relatively shorter anterolateral and externodorsal rays, respectively, and from other congeners by the relative lengths and angulations of bursal rays, and in the shape of the spicules. Female specimens of $U$. sanguinis sp. n. are differentiated from Uncinaria spp. parasitic in terrestrial mammals by differences in vulval anatomy and the larger size of their eggs, although are morphologically indistinguishable from $U$. lucasi and $U$. hamiltoni. Molecular techniques clearly delimited $U$. sanguinis $\mathrm{sp}$. $\mathrm{n}$. as a distinct novel species. Obtaining baseline data on the parasites of wildlife hosts is important for the investigation of disease and the effective implementation and monitoring of conservation management.
\end{abstract}

Keywords: new species, hookworms, conservation, phylogeny, pinnipeds

This article contains supporting information (Tables S1, S2) online at http://folia.paru.cas.cz/supp1/2014-3-255.pdf

Hookworms of the genus Uncinaria Frölich, 1789 (Nematoda: Ancylostomatidae) are haematophagous parasitic nematodes of the small intestine. Eleven species have been described in carnivores (Mammalia: Carnivora) and three additional species described in rodents (Rodentia), tenrecs (Afrosoricida) and treeshrews (Scandentia). The validity of several species has been disputed as a result of unproven host specificity and the questionable significance of some morphological differences (Ransom 1924, Baylis 1933, Olsen 1968, Beveridge 1980). Molecular techniques coupled with morphological analysis can reduce the uncertainty of species delimitation and description (Pérez-Ponce de León and Nadler 2010). Baseline knowledge of species identity has significant implications for the management of parasitic diseases and conservation of the host themselves (Thompson et al. 2010).

One of the long-standing parasitological uncertainties is the number of distinct Uncinaria species parasitising pinnipeds (Carnivora) (George-Nascimento et al. 1992, Nadler et al. 2000). Parasites in the genus Uncinaria have been reported from eleven otariid (eared seals) and five phocid (earless seals) hosts (Dailey 2001, Lyons et al. 2011a, Brock et al. 2013, Nadler et al. 2013). Only two species have been described and named, Uncinaria lucasi Stiles, 1901 from the northern fur seal, Callorhinus ursinus (Linnaeus), and Uncinaria hamiltoni Baylis, 1933 from the South American sea lion, Otaria byronia de Blainville; syn. Otaria flavescens (Shaw). However, the existence of greater species diversity has been recently recognised using molecular techniques (Nadler et al. 2000, Lyons et al. 2011b, Nadler et al. 2013, Ramos et al. 2013). Additionally, Nadler et al. (2013) demonstrated reduced host-specificity, showing that $U$. lucasi also parasitises Steller sea lion, Eumetopias jubatus (Schreber), and $U$. hamiltoni also parasitises the South American fur seal, Arctophoca australis (Zimmerman). The taxonomic identity of specimens from other pinniped hosts is unresolved.

In Australian waters, hookworms from the Australian sea lion, Neophoca cinerea (Péron), Australian fur seal, Arctocephalus pusillus doriferus (Wood Jones), and New Zealand fur seal, Arctophoca australis forsteri (Lesson), are traditionally considered closely related and morpho- 
logically similar to U. hamiltoni (Norman 1994, Ramos et al. 2013). Ramos et al. (2013) showed that Uncinaria spp. from Australian pinnipeds are molecularly distinct from North American pinniped hookworms and that the Australian sea lion and New Zealand fur seal may share a single species of Uncinaria.

The aim of the present study was to address whether a single novel species of hookworm parasitises the Australian sea lion. The Australian sea lion is classified as endangered in the IUCN Red List of Threatened Species due to its small, genetically fragmented population, population declines at some colonies, and the risk of extinction from fishery by-catch (Goldsworthy and Gales 2008, McIntosh et al. 2012). We investigated the utility of quantitative morphometrics to delineate Uncinaria species by assessing intra- and inter-host parasite variation and determining the effect of host age on parasite morphometrics. Subsequently, we used molecular techniques to examine the phylogenetic relationships of Uncinaria species. The outcome is a description of a new Uncinaria species.

\section{MATERIALS AND METHODS}

\section{Sample collection}

All samples were collected from Australian sea lion pups. Necropsies were undertaken on pups found dead at Seal Bay, Kangaroo Island $(\mathrm{n}=84)$, Dangerous Reef, Spencer Gulf $(\mathrm{n}=32)$, and South Page Island, Backstairs Passage $(\mathrm{n}=1)$, in South Australia during 2009-2013 as a part of ongoing investigations into the pathogenesis and epidemiology of hookworm infection in the Australian sea lion. A sample of hookworm specimens was collected from the small intestine from fresh carcasses or from frozen-thawed pups and stored in $70 \%$ ethanol at $-20{ }^{\circ} \mathrm{C}$; the remainder of the intestinal content was stored in $10 \%$ neutral buffered formalin. Daily observations of marked and unmarked pups at Seal Bay in 2012 facilitated the collection of hookworm specimens from dead pups of known-age (8-101 days, $n=12)$. All samples were collected under Government of South Australia Department of Environment, Water and Natural Resources Wildlife Ethics Committee approvals (3-2008 and 3-2011) and Scientific Research Permits (A25008/4-8).

\section{Morphological study}

Individual hookworms were examined in temporary glass slide mounts using 4, 10, 20, and 40× objectives of an Olympus BX60 microscope equipped with differential interference contrast (Olympus, Sydney, Australia) and photographed with a ProgRes CFscan camera (Jenoptik, Jena, Germany) or DP80 camera (Olympus). Voucher specimens preserved with 70\% ethanol were cleared and mounted with lactophenol (Rep 1963). Hookworm vouchers used for molecular studies were mounted in $70 \%$ ethanol. Measurements recorded with an ocular micrometer were body length, maximum body width (measured at approximately mid-specimen), buccal capsule length, buccal capsule width, teeth height, oesophageal length, and maximum oesophageal width. Additional measurements recorded from male specimens included spicule length and gubernaculum length, and from female specimens the distance from the vulva to tail tip, tail length, and the average length and width of three eggs per female. Measurements for each feature were not obtained for every specimen due to differences in preservation or clarity. Additional morphological observations were performed with specimens cleared and mounted in glycerol. Specimens obtained from pups with hookworm eggs in their faeces were considered mature, confirmed by the presence of eggs in female hookworms. Measurements given in-text are mean with standard deviation, followed in parentheses by the range and sample size. Values in brackets are measurements for the holotype male or allotype female, as indicated. All measurements are in micrometres, unless otherwise stated.

Z-stack images were created using cellSens Dimensions 1.8.1 (Olympus). All images were imported into Adobe Photoshop CS6 (Adobe Systems, San Jose, USA) and multiple images were combined to illustrate features spanning greater than a single field-of-view. Images were converted to greyscale and adjustment layers for levels and brightness/contrast were used to optimise the appearance of investigated features. Individual specimens were isolated from the background using layer masks and presented on a white background. Line drawings accompany photomicrographs to illustrate characteristic features. The introduction of the new hookworm species name followed generic rules for describing a new (parasite) species (Šlapeta 2013).

\section{Statistical analysis}

Descriptive statistics were used to assess the intra- and interhost morphometric differences between hookworm specimens. The effect of host age on the body length of both male and female hookworms, and on spicule length for male specimens, was assessed with a linear fixed effects model using REML in GenStat 16.1 (VSN International, Hemel Hempstead, UK). Model assumptions were checked by visually assessing the fitted-value plots of residuals for homogeneity of variance and the histograms of residuals for approximately normal distributions. Predicted means were compared using Fisher's Protected LSD $(\alpha=0.05)$. We focused on these features as they may be objectively measured, are unlikely to be substantially influenced by specimen preparation, and are considered important for species discrimination (Baylis 1933, Rep 1963, Nadler et al. 2000).

\section{Morphological identification}

The identification of examined specimens was attempted using taxonomic keys and species descriptions (Baylis 1933, 1947, Maplestone 1939, Chabaud et al. 1964, Olsen 1968, Chabaud and Durette-Desset 1975, Beveridge 1980, Hasegawa 1989, Lichtenfels 2009, Willmott and Chabaud 2009).

\section{Molecular characterisation}

An approximately $4 \mathrm{~mm}$ mid-body section was excised aseptically using a sterile scalpel blade from individual hookworms collected from Seal Bay ( $\mathrm{n}=10 ; 10$ hosts), Dangerous Reef $(\mathrm{n}=10 ; 8$ hosts) and South Page Island $(\mathrm{n}=1)$. The anterior and posterior ends were retained as voucher specimens. The midsection of each hookworm was air dried prior to DNA extraction. DNA was extracted from mid-body sections using the standard protocol of the Isolate II Genomic DNA Kit (Bioline, Sydney, Australia).

Two regions of nuclear ribosomal DNA (rDNA) encompassing the internal transcribed spacers (ITS1 and ITS2) and a partial sequence of the $28 \mathrm{~S}$ rDNA were amplified by PCR using primers No. 93/No. 94 and No. 527/No. 532, respectively (Nadler et al. 2000). PCR was performed using $15 \mu 1$ MyTaq Red Mix (Bioline), 5 pmol of each primer, and $2 \mu 1$ template DNA in 
a total volume of $30 \mu 1$. Cycling parameters consisted of an initial denaturation at $94^{\circ} \mathrm{C}$ for $5 \mathrm{~min}$, followed by 30 or 35 cycles of $94^{\circ} \mathrm{C}$ for $15 \mathrm{~s}, 54^{\circ} \mathrm{C}$ for $15 \mathrm{~s}, 72^{\circ} \mathrm{C}$ for $15 \mathrm{~s}$, and a final extension at $72^{\circ} \mathrm{C}$ for $2 \mathrm{~min}$. Sequence polymorphism was verified by PCR with an alternate polymerase master mix, EconoTaq PLUS GREEN (Lucigen, Middleton, USA), using the same parameters described above. Successful amplification was confirmed by gel electrophoresis using a 1.5\% agarose gel with GelRed (Biotium, Hayward, USA). Amplicons were bidirectionally sequenced using PCR primers at Macrogen Inc. (Seoul, South Korea). Sequences were assembled and analysed with CLC Main Workbench 6.8.1 (CLC bio, Aarhus, Denmark).

Obtained sequences were aligned with hookworm sequences from the otariid hosts Australian fur seal (ITS: HE962177; 28S rDNA: HQ261929), New Zealand fur seal (ITS region only: HE962175), New Zealand sea lion, Phocarctos hookeri (Gray) (HQ262095; HQ261983), South American sea lion (HQ262119; HQ262006), South American fur seal (HQ262102; HQ261989), Steller sea lion (HQ262131; HQ262018), northern fur seal (AF217890; AF257730), and California sea lion, Zalophus californianus (Lesson) (AF217889; AF257724), and from the phocid hosts southern elephant seal, Mirounga leonina (Linnaeus) (HE962181; HQ262009), and Mediterranean monk seal, Monachus monachus Hermann (HQ262065; HQ261951). An Australian sea lion hookworm sequence (ITS region only: HE962176), collected from Dangerous Reef in 1994 (Ramos et al. 2013), was included for historical comparison. Uncinaria stenocephala Railliet, 1884 (AF194145; AF257712) from the Arctic fox, Alopex lagopus (Linnaeus), and Uncinaria felidis Maplestone, 1939 (Shimono et al. 2012; ITS2 only) from the Tsushima leopard cat, Prionailurus bengalensis euptilura (Elliott), were included for outgroup comparisons. The numbering of sequence residues is according to rDNA unit of Caenorhabditis elegans (Maupas, 1900) (X03680).

Multiple sequence alignment was constructed using ClustalW 1.83 (Thompson et al. 1994). Comparisons were performed for the ITS1, ITS2 and 28S rDNA regions to determine percentage sequence similarity (uncorrected p-distance) using CLC Main Workbench. Phylogenetic analyses were performed using a concatenated DNA dataset. The best-fit model of DNA evolution was selected based on the lowest Bayesian Information Criterion using MEGA 5.2.1 (Tamura et al. 2011). Bayesian trees were constructed using MrBayes 3.2.2 (Ronquist et al. 2012). The parameters were set to Kimura- 2 parameter model and run for 2000000 generations with sampling every 200 generations with four chains (temperature set to 0.2 ). The analysis was run beyond convergence and run multiple times.

The consensus tree was constructed and posterior probabilities calculated from the dataset from which the first 500000 generations were discarded. Maximum Parsimony and Maximum Likelihood trees were calculated using MEGA 5.2.1 (Tamura et al. 2011). The Maximum Parsimony tree was obtained using the Subtree-Pruning-Regrafting algorithm with search level 1 in which the initial trees were obtained by the random addition of sequences (10 replicates). The initial Maximum Likelihood search was started from a tree reconstructed using the Neighbour-Joining method with distances estimated using the Maximum Composite Likelihood approach. Bootstrap support was calculated from 1000 replicates. A schematic tree of the phylogeny demonstrating character state changes was constructed from the majority consensus of the three phylogenetic analyses.

\section{RESULTS}

Morphological and molecular data of nematodes recovered from the Australian sea lion have revealed an undescribed hookworm species. Our current investigation forms the basis for a formal description of a new parasite species belonging to the genus Uncinaria.

\section{Uncinaria sanguinis $\mathrm{sp} . \mathrm{n}$.}

Figs. 1-14

Description: Small, translucent, white nematodes with occasional dark-red intestinal contents. Sexual dimorphism evident in mature specimens (Figs. 1, 2). Anterior extremity bent dorsally (Figs. 4, 6). Ventricose-shaped oral opening armed with paired anterior and posterior cutting plates (Figs. 3-6). Four small submedian papillae present around oral opening (Fig. 5), amphids not observed. Buccal capsule large and globular with continuous walls. Dorsal gutter present. Bilateral teeth with variably shaped tips arise ventrally, anterior to the annular thickening of buccal capsule. Oesophagus elongate, posteriorly clavate. Paired lateral deirids, small, present in mid-oesophageal region (Fig. 6). Nerve ring in midoesophageal region (Fig. 6). Excretory pore opens ventrally, in mid-oesophageal region (Fig. 6).

Male (description based on 116 specimens; for detailed morphometric data - see Tables 1,2): Total body length $9.1 \pm 1.7(3.8-11.5 ; 46)$ [8.8] mm; juvenile (8-14 days) $7.2 \pm 1.7(3.8-8.9 ; 9) \mathrm{mm}$, mature (15-39 days) $10.1 \pm 1.0$ $(8.5-11.5$; 15) mm. Maximum body width $390 \pm 67$ (165-470; 46) [400]. Buccal capsule length $239 \pm 21$ (163-280; 37) [260], width $216 \pm 21(175-270 ; 37)$ [270]. Teeth height $45.4 \pm 11.7(25-80 ; 20)$ [60]. Oesophageal length $965 \pm 126(650-1275 ; 33)$ [900], width $169 \pm 32$ (70-220; 33) [170]. Copulatory bursa symmetrical with single dorsal lobe, paired lateral and ventral lobes (Figs. 10, 11). Paired lateroventral prebursal papillae, small, anterior to copulatory bursa. Dorsal ray bifurcates distally with each short stem terminating in 3 digitations. Externodorsal ray arises proximally from dorsal ray, does not reach edge of lateral lobe. Lateral rays in contact proximally, separated for distal half; anterolateral ray shorter than other lateral rays; mediolateral and posterolateral rays approximately equal in size, tips reach edge of lateral lobe. Lateroventral and ventroventral rays equal in length and fused, tips reach edge of ventral lobe. Gubernaculum elongate, posteriorly clavate; length $104 \pm 22$ (50-150; 24) [105]. Paired spicules, length $762 \pm 47(660-860 ; 34)$ [670]; juvenile (8-14 days) $748 \pm 51$ (660-800; 6), mature (15-39 days) $733 \pm 39(670-800 ; 8)$. Spicules feature transverse striations and sharp tips. Genital cone prominent with long, thin, bilaterally paired papillae present near posterior margin.

Female (description based on 112 specimens; for detailed morphometric data - see Tables 1, 2): Total body length $13.5 \pm 3.5(4.5-20.2 ; 52)$ [13.3] mm; juvenile $(8-14$ days) $8.9 \pm 1.8(5.3-11.0 ; 7) \mathrm{mm}$, mature 

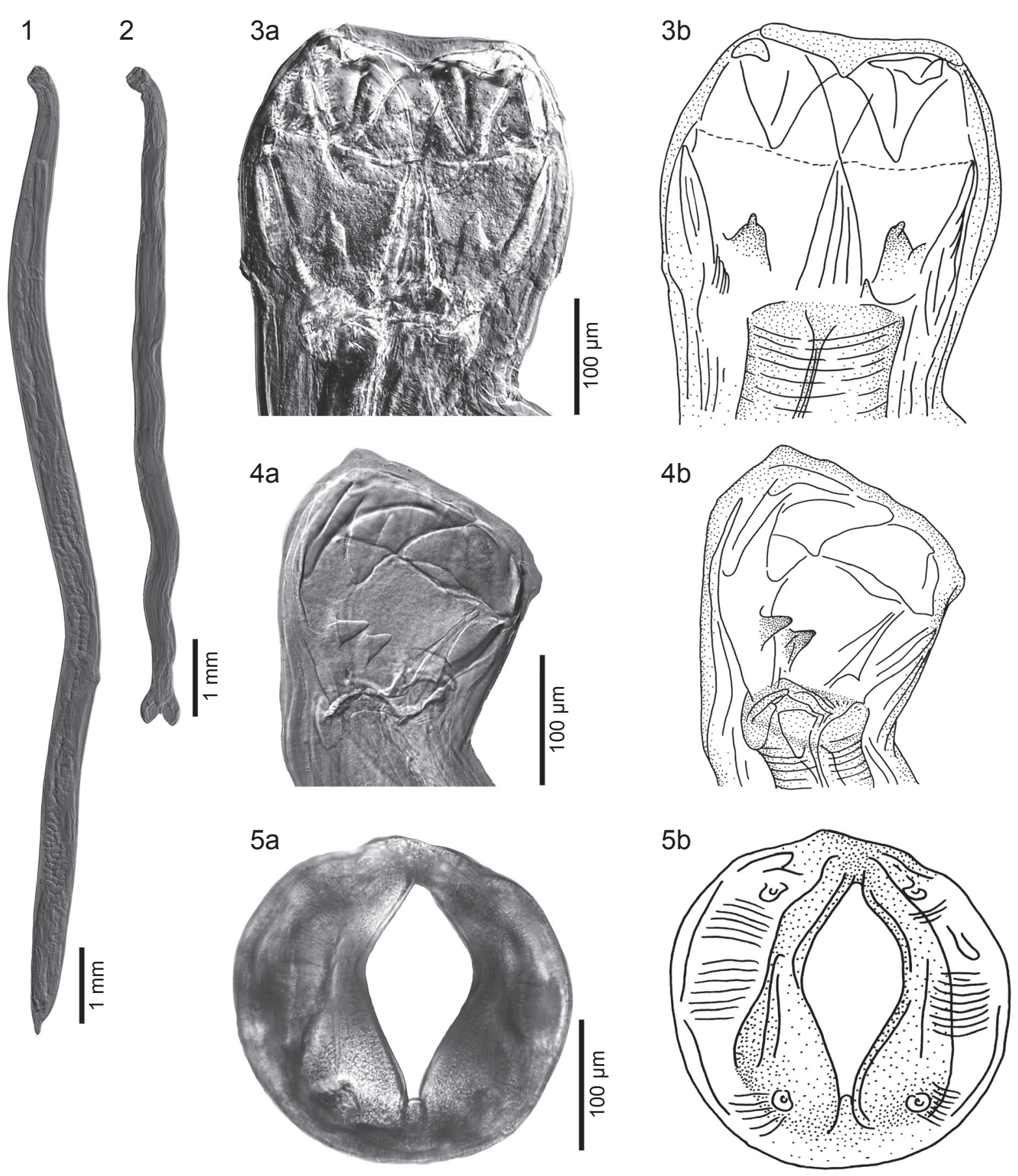

Figs. 1-5. Photomicrographs (a) and line drawings (b) of Uncinaria sanguinis sp. n. from Australian sea lion (Neophoca cinerea). Fig. 1. Allotype female. Fig. 2. Holotype male. Fig. 3. Holotype male, buccal capsule, dorsoventral view. Fig. 4. Juvenile male, buccal capsule, oblique lateral view. Fig. 5. Female, buccal capsule, en face view.

(15-101 days) $15.0 \pm 1.7(12.4-18.5 ; 17) \mathrm{mm}$. Maximum body width $451 \pm 90(110-590 ; 52)$ [520]. Buccal capsule length $287 \pm 31(200-330 ; 25)$ [300], width $257 \pm 24$ (185-300; 25) [265]. Teeth height $54 \pm 12$ (38-75; 17) [75]. Oesophageal length $1059 \pm 130(750-1275 ; 25)$ [1000], width $183 \pm 37(90-240 ; 25)$ [170]. Tail bluntly conical, length $204 \pm 39(150-285 ; 27)$ [225], terminating with a short spike (Fig. 8). Vulva located in middle to posterior third of body, $5.2 \pm 1.6(1.8-9.8 ; 29)[5.0] \mathrm{mm}$ to posterior end; prominent anterior and posterior vulval lips (Fig. 7). Ovejectors longitudinal; uterine eggs thin shelled, elliptical, $124 \pm 6 \times 81 \pm 9(110-135 \times 55-95$; 19) $[123 \times 80]$ (Fig. 9).

Type host: Australian sea lion, Neophoca cinerea (Péron), emaciated and freshly deceased pup, female, 15 days old, $6 \mathrm{~kg}$, collected 1 May 2012 (ID SBDP12-088). 
$6 a$
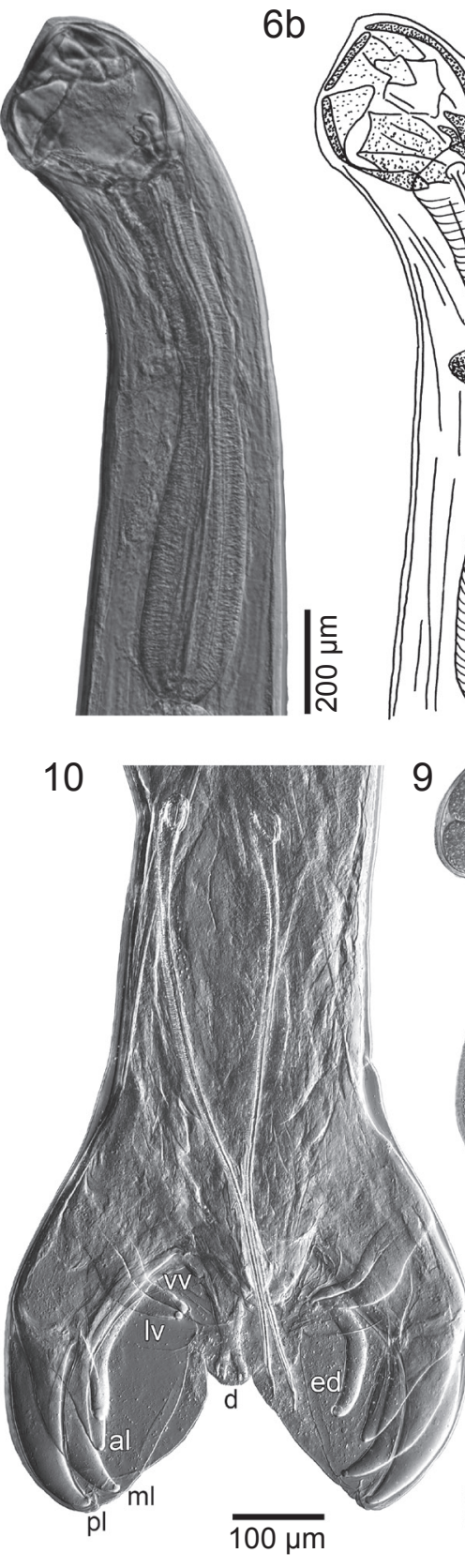

$7 a$
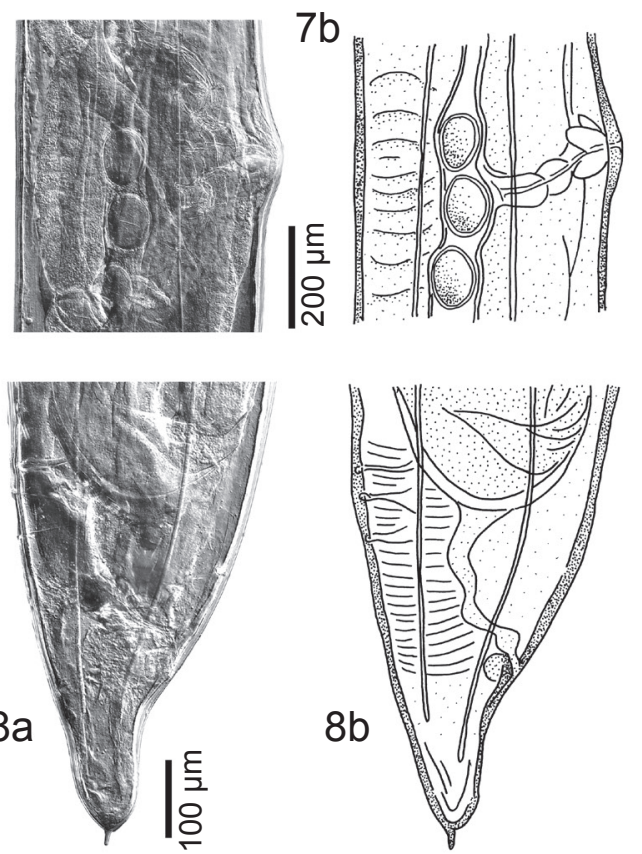

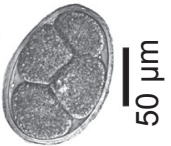

$11 \mathrm{a}$
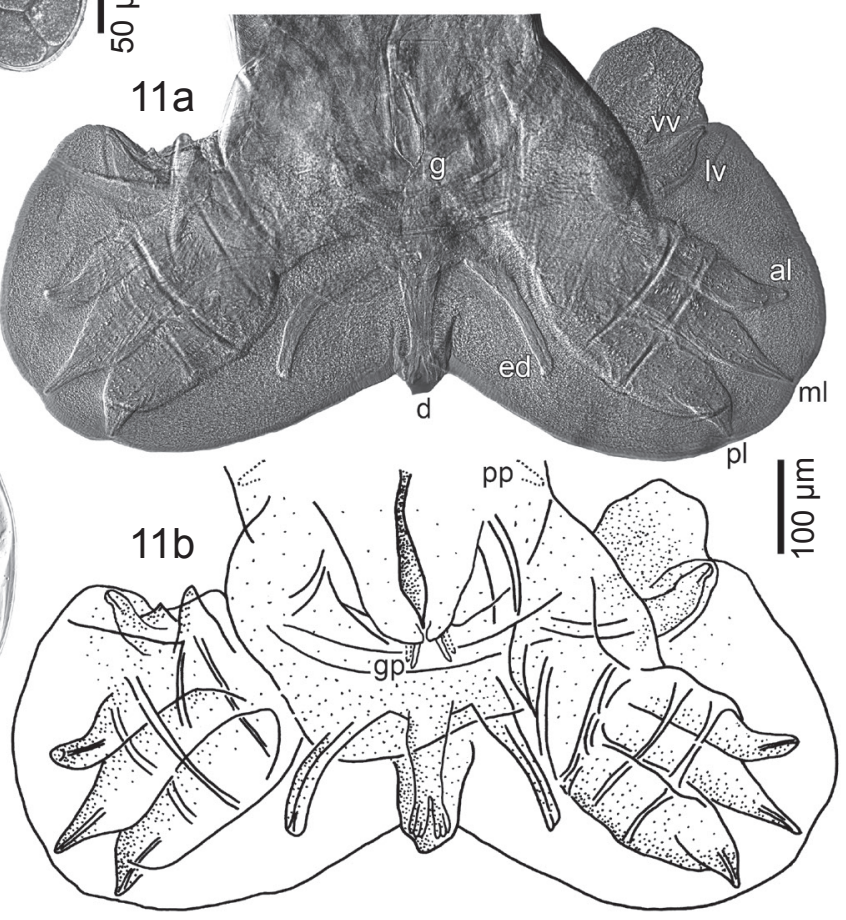

Figs. 6-11. Photomicrographs (a) and line drawings (b) of Uncinaria sanguinis sp. n. from Australian sea lion (Neophoca cinerea). Fig. 6. Allotype female, anterior end, lateral view. Fig. 7. Allotype female, vulva, lateral view. Fig. 8. Allotype female, tail with mucron, lateral view. Fig. 9. Ovum. Fig. 10. Holotype male, copulatory bursa and spicules, dorsoventral view. Fig. 11. Male, copulatory bursa and gubernaculum, dorsoventral view with rays spread. Abbreviations: al - anterolateral; $\mathrm{d}$ - dorsal; ed - externodorsal; $\mathrm{g}$ - gubernaculum; gp - genital cone papillae; lv - lateroventral; $\mathrm{ml}$ - mediolateral; $\mathrm{pl}$ - posterolateral; $\mathrm{pp}$ - prebursal papillae; $\mathrm{vV}-$ ventroventral.

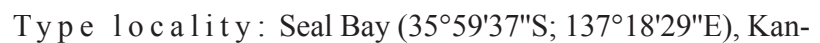
garoo Island, South Australia, Australia.

O the r 1 o c a liti e s: Seal Bay, Kangaroo Island (35'59'40"S; $\left.137^{\circ} 19^{\prime} 00^{\prime \prime} \mathrm{E}\right)$, Dangerous Reef, Spencer Gulf (344' $54^{\prime \prime S}$; $\left.136^{\circ} 12^{\prime} 43^{\prime \prime E}\right)$, and South Page Island, Backstairs Passage (3546'37"S; 138¹7'31"E); South Australia, Australia.
Site of infection: Based on necropsy, adult and juvenile worms in large numbers in the small intestine of Australian sea lion pups. Unembryonated eggs released into the environment with faeces.

Type specimens: Holotype male (AHC 35806), allotype female (AHC 35807), and 58 paratypes (AHC 35808 and 
Table 1. Measurements of Uncinaria sanguinis sp. n. collected from Australian sea lion (Neophoca cinerea) pups.

\begin{tabular}{lcccccccc}
\hline $\begin{array}{l}\text { Location } \\
\text { Sex }\end{array}$ & DR & $\begin{array}{c}\text { SPI } \\
\text { Mature } \text { + }\end{array}$ & Seal Bay & $\begin{array}{c}\text { Seal Bay } \\
\text { Juvenile }+\end{array}$ & DR & $\begin{array}{c}\text { SPI } \\
\text { Mature } \delta^{\lambda}\end{array}$ & Seal Bay & $\begin{array}{c}\text { Seal Bay } \\
\text { Juvenile } \delta^{\wedge}\end{array}$ \\
\hline Max. sample size & 17 & 1 & 24 & 10 & 14 & 1 & 20 & 11 \\
Hosts examined & 10 & 1 & 13 & 7 & 8 & 1 & 10 & 6 \\
Body length & $10.2-20.2(6.0)$ & 16.9 & $10.1-18.7(4.0)$ & $4.5-11(2.2)$ & $6.6-11.4(1.4)$ & 10.1 & $8.5-11.5(2.0)$ & $3.8-8.9(3.8)$ \\
Body width & $450-590(100)$ & 540 & $320-580(140)$ & $110-380(10)$ & $350-450(50)$ & 460 & $350-470(50)$ & $165-380(85)$ \\
Buccal capsule length & $250-330(30)$ & - & $255-320(15)$ & $200-275(-)$ & $220-265(15)$ & 220 & $215-280(50)$ & $163-250(50)$ \\
Buccal capsule width & $235-300(50)$ & - & $225-300(10)$ & $185-275(-)$ & $175-225(35)$ & 190 & $190-270(40)$ & $180-250(25)$ \\
Teeth height & $40-75(15)$ & - & $50-75(-)$ & $38-60(-)$ & $35-50(15)$ & - & $40-80(35)$ & $25-45(-)$ \\
Oesophageal length & $1000-1150(40)$ & - & $1000-1275(125)$ & $750-1000(-)$ & $850-1050(150)$ & 1025 & $900-1275(25)$ & $650-900(100)$ \\
Oesophageal width & $120-230(50)$ & - & $170-240(0)$ & $90-195(-)$ & $125-195(55)$ & 165 & $160-220(35)$ & $70-180(50)$ \\
Tail length & $160-285(35)$ & 245 & $150-275(95)$ & $150-235(-)$ & - & - & - & - \\
Vulva to posterior end & $3.5-9.8(0.9)$ & 7.0 & $4.6-7.4(1.9)$ & $1.8-4.1(-)$ & - & - & - & - \\
Average egg length & $110-128(15)$ & - & $115-135(8)$ & - & - & - & - & - \\
Average egg width & $73-95(7)$ & - & $55-88(33)$ & - & - & - & - & - \\
Gubernaculum length & - & - & - & - & $50-100(50)$ & - & $90-150(45)$ & $75-125(50)$ \\
Spicule length & - & - & - & - & $680-850(110)$ & 760 & $670-860(60)$ & $660-800(110)$ \\
\hline
\end{tabular}

Measurements are given in mm for body length and vulva to posterior end. All other measurements are in $\mu \mathrm{m}$. Reported values are minimum-maximum. Values in parentheses are the maximum range observed within individual hosts. Abbreviations: DR - Dangerous Reef; SPI - South Page Island.

Table 2. Comparative measurements (mean \pm standard deviation) of body and spicule lengths for Uncinaria sanguinis sp. $\mathrm{n}$. collected from Australian sea lion (Neophoca cinerea) pups of known age.

\begin{tabular}{|c|c|c|c|c|c|c|c|}
\hline & \multirow[b]{2}{*}{ Pup age (days) } & \multicolumn{4}{|c|}{ Body length (mm) } & \multicolumn{2}{|c|}{ Spicule length $(\mu \mathrm{m})$} \\
\hline & & $\mathrm{n}$ & q & $\mathrm{n}$ & $\hat{0}$ & $\mathrm{n}$ & 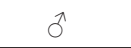 \\
\hline \multirow{4}{*}{ Juvenile } & 8 & 1 & $5.25^{\mathrm{a}}$ & 3 & $5.48^{\mathrm{a}} \pm 1.89$ & 2 & $790 \pm 14$ \\
\hline & 11 & 2 & $9.70^{b} \pm 0.42$ & 2 & $8.12^{\mathrm{b}} \pm 0.18$ & - & - \\
\hline & 12 & 2 & $8.75^{b} \pm 0.35$ & 2 & $8.25^{\mathrm{b}} \pm 0.00$ & 2 & $740 \pm 28$ \\
\hline & 14 & 2 & $9.90^{b} \pm 1.56$ & 2 & $7.94^{b} \pm 1.33$ & 2 & $715 \pm 78$ \\
\hline \multirow{6}{*}{ Mature } & 15 & 4 & $13.18^{\mathrm{c}} \pm 0.64$ & 4 & $9.12^{\mathrm{bc}} \pm 1.01$ & 2 & $735 \pm 92$ \\
\hline & 27 & 4 & $16.38^{\mathrm{d}} \pm 1.49$ & 3 & $10.52^{\mathrm{c}} \pm 0.96$ & 2 & $735 \pm 21$ \\
\hline & 29 & 3 & $14.33^{\mathrm{ce}} \pm 0.26$ & 4 & $9.95^{\mathrm{bc}} \pm 0.77$ & 3 & $723 \pm 25$ \\
\hline & 37 & 2 & $14.88^{\text {cde }} \pm 1.77$ & 2 & $10.62^{\mathrm{c}} \pm 0.53$ & - & - \\
\hline & 39 & 2 & $16.38^{\mathrm{de}} \pm 0.53$ & 2 & $11.00^{c} \pm 0.35$ & 1 & 750 \\
\hline & 101 & 2 & $15.75^{\mathrm{de}} \pm 2.83$ & - & - & - & - \\
\hline
\end{tabular}

For each sex, means that do not share a superscript letter $(\mathrm{a}-\mathrm{e})$ are significantly different $(\mathrm{P}<0.05)$.

AHC 46823-46850) deposited in the Australian Helminthological Collection of the South Australian Museum, Adelaide, Australia. Additional paratypes deposited in the U.S. National Parasite Collection, Maryland, USA (USNPC 107521-107522; $\mathrm{n}=20$ ), Natural History Museum, London, UK (NHMUK 2013.11.13.1-2013.11.13.20; $\mathrm{n}=20$ ), and Helminthological Collection of the Institute of Parasitology, České Budějovice, Czech Republic (IPCAS N-1047; n=2).

DNA sequences (GenBank accession numbers ): Partial 28S rDNA: KF690639-KF690649; ITS1, 5.8S rDNA, ITS2: KF690650-KF690670.

Etymology: The species epithet reflects the haemorrhage and effective exsanguination caused by large burdens of this parasite in the type host. The name is derived as Latin singular genitive.

Morphometrical variation. Measurements were obtained for examined features with inter-host morphometrical variation being greater than intra-host variation (Ta- ble 1). Ranges of all morphometrical features overlapped for mature hookworms from Seal Bay, Dangerous Reef and South Page Island. Juvenile hookworms, collected from pups at Seal Bay with prepatent infections, differed from mature specimens by the absence of eggs in females and generally reduced magnitude for morphometrical values, however, no functional morphological differences were identified (Fig. 4).

Host age and hookworm sex significantly influenced hookworm body length $\left(\mathrm{F}_{8,29}=3.89, \mathrm{P}=0.003\right)$, with significant sexual dimorphism, associated with maturity, observed from 15 days (females longer than males, $\mathrm{P}<0.05$; Table 2). Whilst body length generally increased with host age and mature females were significantly longer than juvenile females $(\mathrm{P}<0.05)$, males at 15 and 29 days were not significantly longer than juvenile males $(\mathrm{P}>0.05)$. Additionally, spicule length was not significantly related to host age $\left(\mathrm{F}_{6,7}=0.49, \mathrm{P}=0.796\right)$. 
12

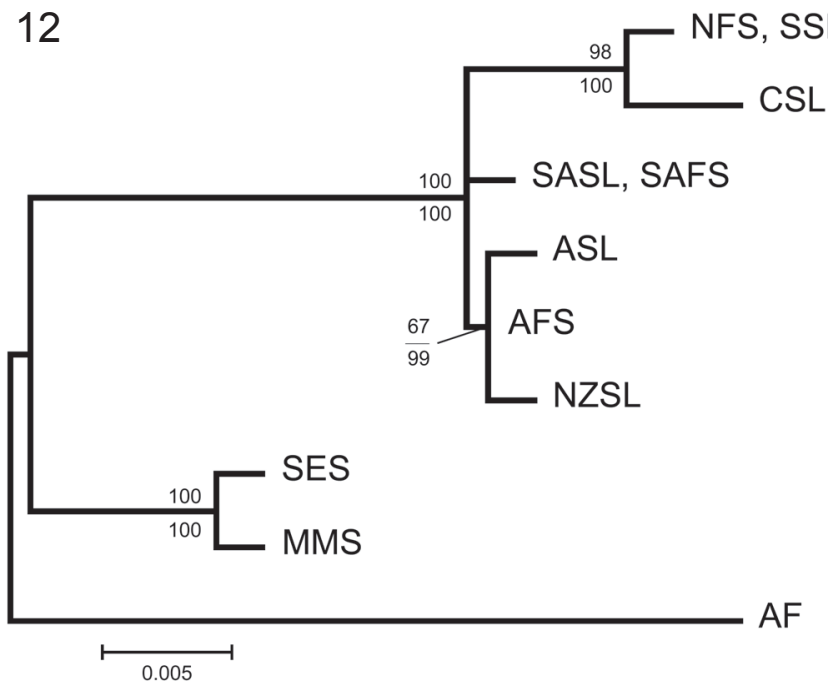

13

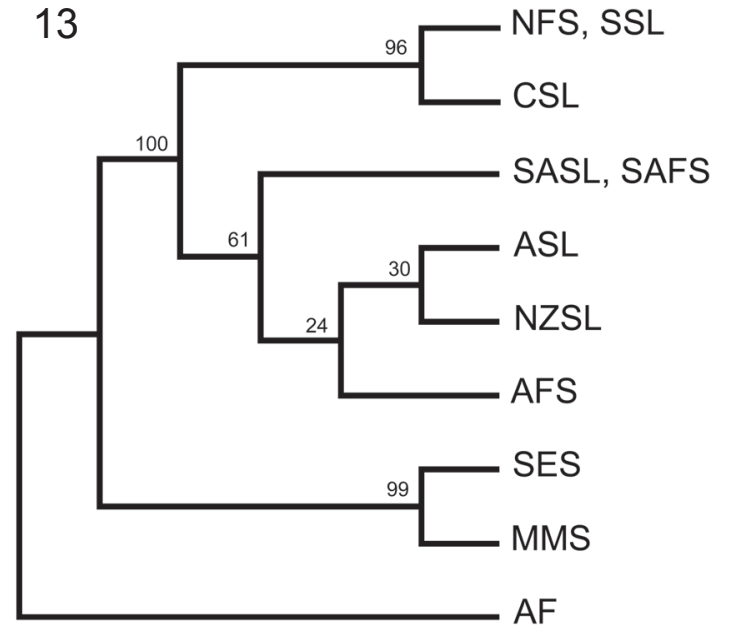

Figs. 12, 13. Phylogenetic relationships of host-associated Uncinaria spp. estimated with concatenated ITS1, ITS2, and 28S rDNA sequence data. Fig. 12. Maximum Likelihood tree based on the K2 model in MEGA5 with the highest log likelihood (-2117.3390). Numbers above the nodes represent bootstrap values (1000 replicates), values below the branches represent Bayesian posterior probabilities based on the $\mathrm{K} 2$ model calculated in MrBayes. The tree is drawn to scale, with branch lengths measured in the number of substitutions per site. Fig. 13. The majority consensus rule tree constructed using Maximum Parsimony based on SPR algorithm in MEGA5. Numbers above the nodes represent bootstrap values (1 000 replicates). The multiple sequence alignment included nine nucleotide sequences and a total of 1149 positions in the final dataset. Abbreviations: AF - Arctic fox, Alopex lagopus; AFS - Australian fur seal, Arctocephalus pusillus doriferus; ASL - Australian sea lion, Neophoca cinerea; CSL - California sea lion, Zalophus californianus; MMS - Mediterranean monk seal, Monachus monachus; NZSL - New Zealand sea lion, Phocarctos hookeri; NFS - northern fur seal, Callorhinus ursinus; SASL - South American sea lion, Otaria byronia; SAFS - South American fur seal, Arctophoca australis; SES - southern elephant seal, Mirounga leonina; SSL - Steller sea lion, Eumetopias jubatus.

DNA sequences. Four DNA markers were amplified. The complete ITS1 of $U$. sanguinis was 364 bp long, ITS2 was $227 \mathrm{bp}$ long and the 5.8S rDNA sequence of $U$. sanguinis was 153 bp long (Seal Bay, $\mathrm{n}=10$; Dangerous Reef, $\mathrm{n}=10$; South Page Island, $\mathrm{n}=1$ ). The partial 28S rDNA sequence of $U$. sanguinis was 992 bp long (Seal Bay, $\mathrm{n}=5$; Dangerous Reef, $\mathrm{n}=5$; South Page Island, $\mathrm{n}=1$ ).

Molecular distance analysis. Uncinaria sanguinis from Seal Bay, Dangerous Reef and South Page Island demonstrated $100 \%$ sequence similarity at ITS1, ITS2, 5.8S rDNA, and 28S rDNA. There was a single polymorphism $(\mathrm{C} / \mathrm{T})$ in ITS1 at position 199 in one worm (AHC 46824; KF690651), which was not present in another worm from the same host (AHC 46825; KF690652). The polymorphism was confirmed by sequencing PCR product generated using two different DNA polymerases. The historical Australian sea lion and New Zealand fur seal hookworm ITS sequences (HE962176 and HE962175, respectively) demonstrated $100 \%$ similarity to U. sanguinis sequences. Additionally, the New Zealand fur seal hookworm ITS sequence (HE962175) demonstrated an ambiguous nucleotide at position 199 in ITS1, corresponding to the polymorphic site in worm AHC 46824 (KF690651). Pairwise comparisons with Uncinaria from other otariid, phocid, canid and felid hosts demonstrated high levels of sequence similarities at ITS1 and ITS2 (Table S1). Fewer differences were evident between hookworm species at the $28 \mathrm{~S}$ rDNA locus; sequence similarity to $U$. sanguinis was 99.3-99.8\% (Table S2). The 5.8s rDNA locus was invariant across all Uncinaria species.

Molecular character analysis. Bayesian analysis demonstrated $100 \%$ support (posterior probability) for one phocid and three otariid hookworm-clades (Figs. 12, 14). The phocid clade consists of two sequences, representing two putative new species, one each from the southern elephant seal and the Mediterranean monk seal. The otariid clade is further divided into the North and South American clades and the Oceanic clade (Figs. 12, 14). The North American otariid clade contains sequences belonging to $U$. lucasi from the northern fur seal and the Steller sea lion, and sequences belonging to the putative new species Uncinaria 'species A' sensu Nadler et al. (2000) from the California sea lion. The South American otariid clade consists exclusively of sequences belonging to $U$. hamiltoni from the South American sea lion and the South American fur seal. The Oceanic otariid clade consists of sequences belonging to $U$. sanguinis from the Australian sea lion and two sequences from unnamed Uncinaria spp. from the New Zealand sea lion and the Australian fur seal, respectively. Hookworms from the New Zealand fur seal are provisionally considered to be U. sanguinis sp. n. on the basis of limited data.

Maximum Likelihood and Maximum Parsimony analyses provided $100 \%$ bootstrap support for separate phocid and otariid hookworm-clades (Figs. 12-14). The Maximum Likelihood analysis demonstrated 100\% support for 


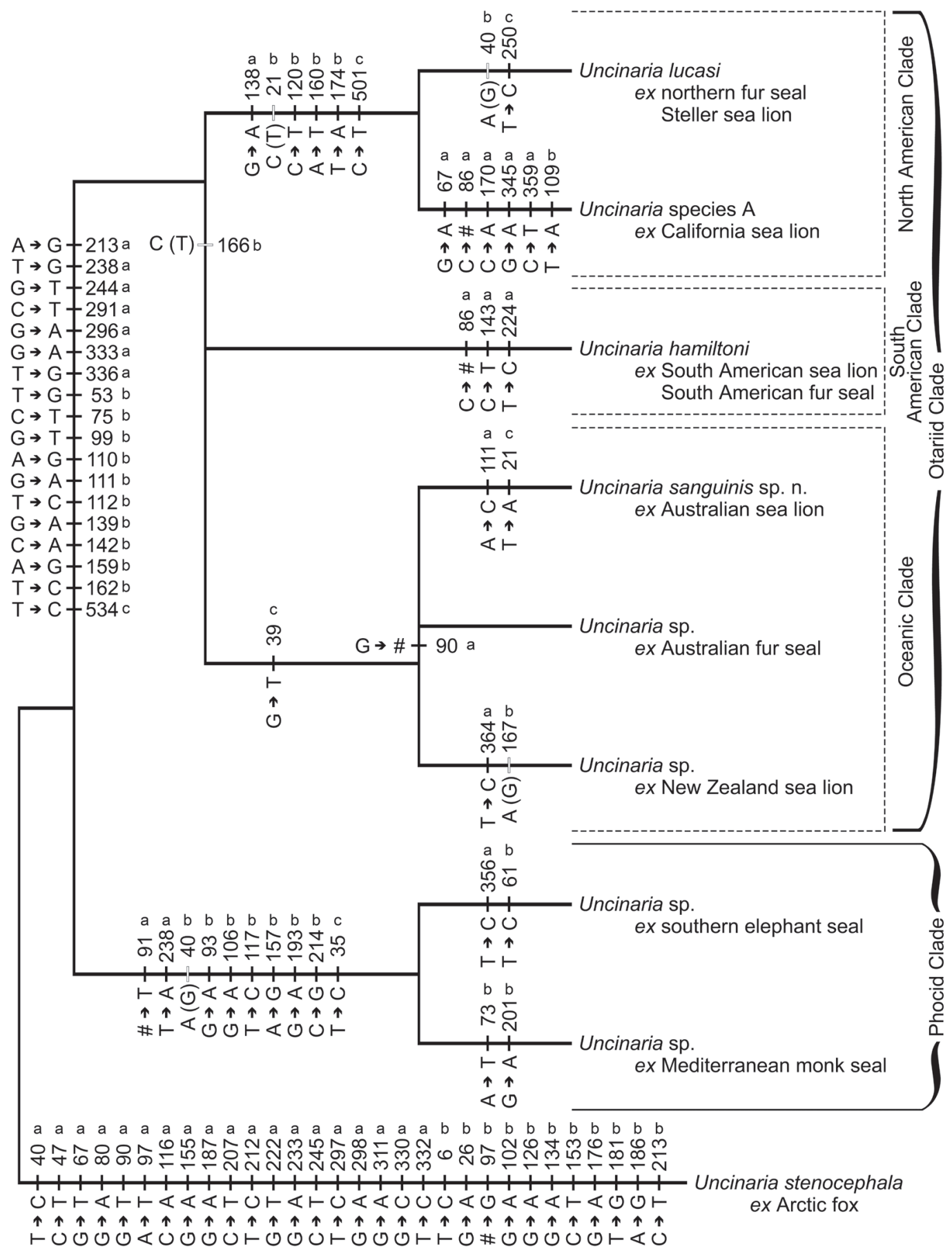

Fig. 14. Schematic of phylogenetic relationships of pinniped Uncinaria spp. constructed from the majority consensus of Bayesian inference, Maximum Likelihood and Maximum Parsimony methods with concatenated ITS1, ITS2, and 28S rDNA sequence data. Uncinaria felidis and Uncinaria sp. from Arctophoca forsteri are excluded due to incomplete data. The bars indicate nucleotide character changes with reference to the outgroup Uncinaria stenocephala. Homoplastic characters shared with U. stenocephala are indicated by white bars with the derived character state at this position indicated in parentheses. Nucleotide gaps are indicated by '\#'. Alignment positions are specific to each locus ( - ITS1; b - ITS2; c-28S rDNA). Four clades are evident, one from phocid hosts and three from otariid hosts.

three otariid hookworm-clades and moderate (67\%) support for the three sequence lineages within the Oceanic clade (Fig. 12). The Maximum Parsimony analysis moderately $(61 \%)$ supported the South American and Oceanic clades and, in contrast to the other phylogenetic analyses, provided only weak $(<50 \%)$ support for separate sequences within the Oceanic clade (Fig. 13). However, fixed rDNA character state changes provide evidence for 
independent evolutionary lineages and species delimitation (Fig. 14).

Differential diagnosis. Uncinaria sanguinis demonstrates the general morphological characteristics of the Ancylostomatinae and the specific features of the genus Uncinaria, including the dorsally directed anterior extremity, a globular buccal capsule with continuous walls, well-developed cutting plates, and a dorsal gutter (Lichtenfels 2009). The species can be differentiated from all other named species in the genus Uncinaria on the basis of morphological features and available molecular data. Morphologically, U. sanguinis is very similar to the otariid hookworms $U$. lucasi and U. hamiltoni, demonstrating subtle morphological differences. An annular thickening of the base of the buccal capsule, observed in $U$. sanguinis and $U$. hamiltoni, was reported absent in the description of $U$. lucasi, but subsequently noted in other specimens (Lyons and DeLong 2005). Male specimens of $U$. sanguinis exhibit shorter anterolateral rays relative to the other lateral rays, a feature shared with $U$. hamiltoni, differentiating these species from $U$. lucasi which exhibits lateral rays of almost equal length (Baylis 1947). The relatively shorter externodorsal rays of $U$. sanguinis distinguish it from U. hamiltoni - see Baylis (1933).

Female specimens of $U$. sanguinis are morphologically indistinguishable from U. lucasi and U. hamiltoni. Uncinaria sanguinis is definitively identified and delimited from $U$. lucasi by thirteen fixed character state changes at three loci (ITS1, $\mathrm{n}=3$; ITS2, $\mathrm{n}=6 ; 28 \mathrm{~S}, \mathrm{n}=4$ ) and from $U$. hamiltoni by seven changes at two loci (ITS1, $\mathrm{n}=5$; 28S, $\mathrm{n}=2$ ).

The size of eggs from $U$. sanguinis is similar to those from $U$. lucasi and U. hamiltoni, and is approximately twice the size of eggs from Uncinaria spp. parasitic in terrestrial mammals, differentiating female otariid hookworms. The only other native Australian hookworm, Uncinaria hydromyidis Beveridge, 1980, described from the Australian water rat, Hydromys chrysogaster Geoffroy, a murid host in north-eastern Queensland, may be further distinguished from $U$. sanguinis by its relatively longer ventral and dorsal rays, blunt spicule tips, the absence of the annular buccal capsule thickening, and female specimens feature inconspicuous vulval lips (Beveridge 1980). Uncinaria bidens (Molin, 1861), found in procyonids (Carnivora), is differentiated from $U$. sanguinis by relatively longer ventral rays and the angulation of the lateral ray tips (Olsen 1968).

The felid hookworms, U. felidis and Uncinaria maya Hasegawa, 1989, differ from U. sanguinis by their posterolateral, externodorsal and dorsal rays being of equal length and female specimens exhibit prevulvar flaps or protruding anterior lips (Maplestone 1939, Hasegawa 1989). Uncinaria bauchoti Chabaud, Brygoo et Tchéprakoff, 1964 and Uncinaria olseni Chabaud et DuretteDesset, 1975, identified from tenrecid (Afrosoricida) and tupaiid (Scandentia) hosts, respectively, exhibit large deirids and have been considered by some authors (Chabaud et al. 1966, Lichtenfels 2009) to represent a subgenus, Megadeirides Chabaud, Bain et Houin, 1966. All other Uncinaria species, found in carnivore hosts from the ailurid, canid, mustelid and ursid families, may be morphologically discriminated from $U$. sanguinis and each other on the basis of their lateral rays using Olsen's (1968) key. Molecularly, U. sanguinis is delimited from $U$. stenocephala by 54 fixed character state changes at three loci (ITS1, $\mathrm{n}=27$; ITS2, $\mathrm{n}=24 ; 28 \mathrm{~S}, \mathrm{n}=3$ ) and from $U$. felidis by 32 changes in ITS2.

\section{DISCUSSION}

Hookworms collected from Australian sea lions were found to belong to a single novel species, Uncinaria sanguinis sp. n. Morphological and molecular investigations did not discriminate between specimens from three South Australian colonies and provided no evidence for the presence of cryptic species or geographical variants. This is the third species within the genus Uncinaria to be described and named from otariid hosts and is morphologically most similar to U. lucasi and U. hamiltoni. Differences in the relative lengths of the bursal rays differentiate these species and fixed rDNA sequence diversity demonstrates independent evolutionary lineages.

The potential for host-induced effects on parasite morphology engenders caution when deciding whether we have new species (George-Nascimento et al. 1992, PérezPonce de León and Nadler 2010). As such, assessing the normal range of morphometric variation within a species is of critical importance for accurate species-description and comparisons. We found little intra-host variation for specimens of $U$. sanguinis from Australian sea lions. Similarly, Olsen and Lyons (1965) reported no variation in the size of $U$. lucasi within individual northern fur seals. These findings support the hypothesis that pinnipeds acquire hookworm infection over a short period of time, likely via the transmammary route shortly after birth (Olsen and Lyons 1965). However, we also observed large morphometric variation between hosts, in part related to host age, highlighting the importance of examining specimens from multiple host-individuals across a range of ages in order to assess the extent of species variation. Interestingly, juvenile hookworms demonstrated no functional morphological differences when compared to adult hookworms and may be associated with host-pathology, which has implications for the detection of disease in live animals.

The wide morphometric ranges we obtained overlap with those of other Uncinaria spp., suggesting limited utility for quantitative morphometrics for species discrimination within this genus. Similar conclusions were reached by other authors who identified significant hostassociated morphometric differences within U. hamiltoni 
from the South American sea lion and South American fur seal (George-Nascimento et al. 1992) and within U. lucasi from the northern fur seal and Steller sea lion (Olsen 1952, Nadler et al. 2013). Whether these differences were host-induced or due to age-dependent variation is unclear due to limited or unreported host sample sizes and unknown host ages. Regardless, these findings support the need to employ molecular techniques to delimit and describe morphologically-similar species.

Hookworms from the Australian fur seal, New Zealand fur seal, and New Zealand sea lion cluster with $U$. sanguinis within the Oceanic clade. Morphological differences between Oceanic hookworms have not been described although molecular differences delineate two species from the Australian fur seal and New Zealand sea lion, respectively, in addition to U. sanguinis from the Australian sea lion. Hookworms from the New Zealand fur seal are thus provisionally considered to be $U$. sanguinis. An alternative viewpoint may be that all hookworms within the Oceanic clade are $U$. sanguinis and that molecular differences reflect intraspecific or geographical variation (Ramos et al. 2013). Whether $U$. sanguinis demonstrates host-specificity or is capable of infecting other hosts remains to be tested. Investigation of hookworm population structure at DNA markers subjected to greater rates of substitution, such as mitochondrial DNA, may demonstrate the level of genetic interchange between colonies and host-associated hookworms and clarify their taxonomic identities further (Gasser and Newton 2000).

Recognising, describing and identifying parasites of free-ranging wildlife species are critical processes for the comprehensive investigation and management of associated disease (Thompson et al. 2010). Delimiting parasitic species is essential for examining host-parasite-environment-anthropogenic interactions, implementing and moni- toring management programs, and ensuring the conservation of parasites and their hosts. Hookworm infection is a recognised cause of morbidity and mortality in otariid hosts (Castinel et al. 2007, Chilvers et al. 2009, DeLong et al. 2009, Spraker and Lander 2010). In this study, we coupled morphological analysis with molecular techniques to describe and identify a novel species of hookworm in the Australian sea lion. This work contributes towards resolving the taxonomic uncertainty within the genus Uncinaria and provides critical data regarding an important pathogen of an endangered mammal. Further investigation and formal identification of the species of hookworms parasitising other pinniped hosts is recommended.

Acknowledgements. We thank the staff at Seal Bay, Department of Environment, Water and Natural Resources for field assistance and the collection of deceased pups, in particular Clarence Kennedy and Janet Simpson; Liisa Ahlstrom, Loreena Butcher, Michael Edwards, Simon Goldsworthy, Claire Higgins, Janet Lackey, Zoe Larum, Theresa Li, Andrew Lowther, Paul Rogers, Laura Schmertmann, Adrian Simon, Ryan Tate, Michael Terkildsen, Mark Whelan, Peter White, Sy Woon, and Mariko Yata for field assistance; Denise McDonell of The University of Sydney for parasite morphology and laboratory assistance; Benjamin Haynes of The University of Sydney for performing the DNA extractions; Carsten Minten of Olympus Australia for use of equipment and assistance with microphotography; Ian Beveridge of The University of Melbourne for helpful comments on hookworm morphology and presentation; and Glenn Shea of The University of Sydney for assistance with Latin grammar. This work was supported by the Australian Marine Mammal Centre, Department of the Environment, Australian Government (grant number 09/17), Winifred Violet Scott Foundation (2007), and the Whitehead Bequest Conservation 2013, Faculty of Veterinary Science, The University of Sydney. We thank the anonymous reviewers and Tomáš Scholz for their constructive comments on the manuscript.

\section{REFERENCES}

BAYLIS H.A. 1933: A new species of the nematode genus Uncinaria from a sea-lion, with some observations on related species. Parasitology 25: 308-316.

BAYlis H.A. 1947: A redescription of Uncinaria lucasi Stiles, a hookworm of seals. Parasitology 38: 160-162.

Beveridge I. 1980: Uncinaria hydromyidis sp. n. (Nematoda: Ancylostomatidae) from the Australian water rat, Hydromys chrysogaster. J. Parasitol. 66: 1027-1031.

Brock P.M., Hall A.J., Goodman S.J., Cruz M., AcevedoWhitehouse K. 2013: Applying the tools of ecological immunology to conservation: a test case in the Galapagos sea lion. Anim. Conserv. 16: 19-31.

Castinel A., Duignan P.J., Pomroy W.E., Lopez-Villalobos N., Gibbs N.J., Chilvers B.L., Wilkinson I.S. 2007: Neonatal mortality in New Zealand sea lions (Phocarctos hookeri) at Sandy Bay, Enderby Island, Auckland Islands from 1998 to 2005. J. Wildl. Dis. 43: 461-474.

Chabaud A.G., Bain O., Houin R. 1966: Nématodes de Potamochères malgaches. Ann. Parasitol. 41: 599-606.
Chabaud A.G., Brygoo E.R., Tchéprakoff R. 1964: Nématodes parasites d'insectivores malgaches. Bull. Mus. Natl. Hist. Nat. 36: 245-261.

Chabaud A.G., Durette-Desset M.-C. 1975: Uncinaria (Megadeirides) olseni $\mathrm{n}$. sp., Nématode à caractères archaïques parasite d'un Tupaia à Bornéo. Ann. Parasitol. Hum. Comp. 50: 789-793.

Chilvers B.L., Duignan P.J., Robertson B.C., Castinel A., Wilkinson I.S. 2009: Effects of hookworms (Uncinaria sp.) on the early growth and survival of New Zealand sea lion (Phocarctos hookeri) pups. Polar Biol. 32: 295-302.

Dailey M.D. 2001: Parasitic Diseases. In: L.A. Dierauf and F.M.D. Gulland (Eds.), CRC Handbook of Marine Mammal Medicine. Second Edition. CRC Press, Florida, pp. 357-382.

DeLong R.L., Orr A.J., Jenkinson R.S., Lyons E.T. 2009: Treatment of northern fur seal (Callorhinus ursinus) pups with ivermectin reduces hookworm-induced mortality. Mar. Mamm. Sci. 25: 944-948. 
Gasser R.B., Newton S.E. 2000: Genomic and genetic research on bursate nematodes: significance, implications and prospects. Int. J. Parasitol. 30: 509-534.

George-Nascimento M., Lima M., Ortiz E. 1992: A case of parasite-mediated competition? Phenotypic differentiation among hookworms Uncinaria sp. (Nematoda: Ancylostomatidae) in sympatric and allopatric populations of South American sea lions Otaria byronia, and fur seals Arctocephalus australis (Carnivora: Otariidae). Mar. Biol. 112: 527-533.

Goldsworthy S.D., Gales N. 2008: Neophoca cinerea. In: IUCN Red List of Threatened Species. Version 2013.2. World Wide Web electronic publication, www.iucnredlist.org, 01/2014.

Hasegawa H. 1989: Two new nematodes from the Iriomote cat, Prionailurus iriomotensis, from Okinawa: Uncinaria (Uncinaria) maya n. sp. (Ancylostomatoidea) and Molineus springsmithi yayeyamanus n. subsp. (Trichostrongyloidea). J. Parasitol. 75: 863-869.

Lichtenfels J.R. 2009: Strongylida. In: R.C. Anderson, A.G. Chabaud and S. Willmott (Eds.), Keys to the Nematode Parasites of Vertebrates: Archival Volume. CABI, Oxfordshire, pp. 44-68.

Lyons E.T., DeLong R.L. 2005: Photomicrographic images of some features of Uncinaria spp. (Nematoda: Ancylostomatidae) from otariid pinnipeds. Parasitol. Res. 95: 346-352.

Lyons E.T., Delong R.L., Nadler S.A., LaAke J.L., Orr A.J., DeLong B.L., Pagan C. 2011b: Investigations of peritoneal and intestinal infections of adult hookworms (Uncinaria spp.) in northern fur seal (Callorhinus ursinus) and California sea lion (Zalophus californianus) pups on San Miguel Island, California (2003). Parasitol. Res. 109: 581-589.

Lyons E.T., Spraker T.R., DeLong R.L., Ionita M., Melin S.R., Nadler S.A., Tolliver S.C. 2011a: Review of research on hookworms (Uncinaria lucasi Stiles, 1901) in northern fur seals (Callorhinus ursinus Linnaeus, 1758). Parasitol. Res. 109: 257-265.

Maplestone P.A. 1939: A new species of Uncinaria Fröhlich, 1789 (Nematoda), with a note on U. stenocephala (Railliet, 1884). Rec. Indian Mus. 41: 219-222.

McIntosh R.R., Goldsworthy S.D., Shaughnessy P.D., Kennedy C.W., Burch P. 2012: Estimating pup production in a mammal with an extended and aseasonal breeding season, the Australian sea lion (Neophoca cinerea). Wildl. Res. 39: 137-148.

Nadler S.A., Adams B.J., Lyons E.T., DeLong R.L., Melin S.R. 2000: Molecular and morphometric evidence for separate species of Uncinaria (Nematoda: Ancylostomatidae) in California sea lions and northern fur seals: hypothesis testing supplants verification. J. Parasitol. 86: 1099-1106.

Nadler S.A., Lyons E.T., Pagan C., Hyman D., Lewis E.E., Beckmen K., Bell C.M., Castinel A., Delong R.L., Duignan P.J., Farinpour C., Huntington K.B., Kuiken T., Morgades D., Naem S., Norman R., Parker C., Ramos P., SPraker T.R., Berón-VEra B. 2013: Molecular systematics of pinniped hookworms (Nematoda: Uncinaria): species delimitation, host associations and host-induced morphometric variation. Int. J. Parasitol. 43: 1119-1132.

Norman R. 1994: Pathology and ecology of hookworm (Uncinaria sp.) infection in a new seal host: the Australian fur seal. In
Proceedings of the Wildlife Disease Association Annual Conference, Dubbo, 24-25 September 1994, pp. 29.

Olsen O.W. 1952: Report on investigations of hookworms, Uncinaria lucasi Stiles, 1901, and hookworm disease of fur seals, Callorhinus ursinus, on the Pribilof Islands, Alaska, from 7 July to September 2, 1951. With a supplemental report by W.L. Jellison, ozalid copy. US Department of Interior, Fish and Wildlife Service, Washington, DC. (Cited after Lyons 2005).

OlsEN O.W. 1968: Uncinaria rauschi (Strongyloidea: Nematoda), a new species of hookworms from Alaskan bears. Can. J. Zool. 46: 1113-1117.

Olsen O.W., Lyons E.T. 1965: Life cycle of Uncinaria lucasi Stiles, 1901 (Nematoda: Ancylostomatidae) of fur seals, Callorhinus ursinus Linn., on the Pribilof Islands, Alaska. J. Parasitol. 51: 689-700.

Pérez-Ponce de León G., Nadler S.A. 2010: What we don't recognize can hurt us: a plea for awareness about cryptic species. J. Parasitol. 96: 453-464.

Ramos P., Lynch M., Hu M., Arnould J.P.Y., Norman R., BevERIDGE I. 2013: Morphometric and molecular characterization of the species of Uncinaria Frölich, 1789 (Nematoda) parasitic in the Australian fur seal Arctocephalus pusillus doriferus (Schreber), with notes on hookworms in three other pinniped hosts. Syst. Parasitol. 85: 65-78.

Ransom B.H. 1924: Hookworms of the genus Uncinaria of the dog, fox, and badger. Proc. U.S. Natl. Mus. 65: 1-5.

Rep B.H. 1963: On the polyxenia of the Ancylostomidae and the validity of the characters used for their differentiation. Trop. Geogr. Med. 15: 173-218.

Ronquist F., Teslenko M., van der Mark P., Ayres D.L., Darling A., Höhna S., Larget B., Liu L., Suchard M.A., Huelsenbeck J.P. 2012: MrBayes 3.2: efficient Bayesian phylogenetic inference and model choice across a large model space. Syst. Biol. 61: 539-542.

Shimono Y., Taharaguchi S., Taira K., Miyoshi N., Yasuda N. 2012: rDNA ITS sequences of Uncinaria spp. from Tsushima leopard cat (Prionailurus bengalensis euptilura). Helminthologia 49: 123-127.

ŠLAPETA J. 2013: Ten simple rules for describing a new (parasite) species. Int. J. Parasitol. Parasites Wildl. 2: 152-154.

Spraker T.R., Lander M.E. 2010: Causes of mortality in northern fur seals (Callorhinus ursinus), St. Paul Island, Pribilof Islands, Alaska, 1986-2006. J. Wildl. Dis. 46: 450-473.

Tamura K., Peterson D., Peterson N., Stecher G., Nei M., KumAR S. 2011: MEGA5: molecular evolutionary genetics analysis using maximum likelihood, evolutionary distance, and maximum parsimony methods. Mol. Biol. Evol. 28: 2731-2739.

Thompson J.D., Higgins D.G., Gibson T.J. 1994: CLUSTAL W: improving the sensitivity of progressive multiple sequence alignment through sequence weighting, position-specific gap penalties and weight matrix choice. Nucleic. Acids Res. 22: 4673-4680.

Thompson R.C.A., Lymbery A.J., Smith A. 2010: Parasites, emerging disease and wildlife conservation. Int. J. Parasitol. 40: $1163-1170$.

Willmott S., Chabaud A.G. 2009: Glossary and Keys to Subclasses. In: R.C. Anderson, A.G. Chabaud and S. Willmott (Eds.), Keys to the Nematode Parasites of Vertebrates: Archival Volume. CABI, Oxfordshire, pp. 1-17. 